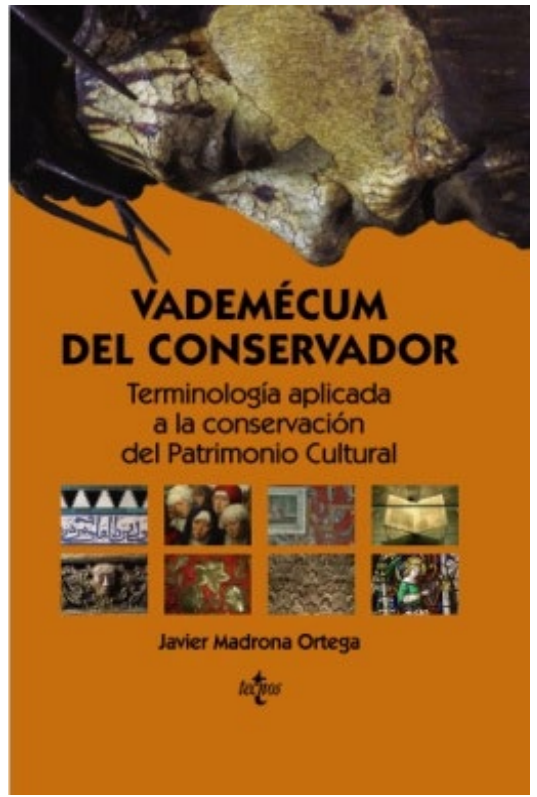

Ambiciosa obra de consulta sobre las técnicas, términos y materiales relacionados con la conservaciónrestauración, que intenta abarcar todas las especialidades del patrimonio, cosa que se agradece ya que en España, hasta ahora, no existía algo así.

Los temas tratados son los reseñados en la bibliografía:

1-Cartas documentos y legislación.

2-Conservación y restauración: conservación preventiva, Criterios: teoría de la restauración. Museología y museografía. Actuación: métodos, análisis y materiales.

3-Pintura de caballete: Pintura sobre tela y sobre tabla

4-Pintura mural

5-Madera tallada, dorada y policromada Soportes celulósicos y proteicos: papel papiro y pergamino.

6-Soportes metálicos.

7-Soportes pétreos: piedra, cerámica vidriada, terracota. Yeso

8-Soportes textiles

\section{Vademécum del Conservador. Terminología aplicada a la conservación del Patrimonio Cultural}

\author{
Javier Madrona Ortega
}

Editor: Tecnos; 2015

Colección: Ventana Abierta

Páginas: 640

Idioma: Español

ISBN: 978-8430965021
9-Soportes vítreos: vidrio, vidrieras

10-Instituciones y organismos tanto nacionales como internacionales. Boletines, catálogos, revistas web.

Llaman la atención las entradas sobre legislación, instituciones, organismos y revistas online, donde se nombran asociaciones como ACESEA (Asociación Española de Centros Superiores de Enseñanza), IPCE, Centro de CR de Castilla la Mancha con su organigrama, ACRE (de la que especifica sus objetivos), ARPA, AIC, ECCO etc... lo que no es habitual en este tipo de textos.

El contenido es un tanto irregular en cuanto a la extensión de los términos, ya que los hay muy completos y bien desarrollados mientras otros no lo son tanto. Menciona marcas registradas, composición, porcentajes y preparación de algunas formulas utilizadas en intervenciones, valora la agresividad de algunos tratamientos, y nos da extensas, sorprendentes, variopintas o útiles descripciones de, por ejemplo, los distintos tipos de resinas, cintas adhesivas, de los clavos y sus denominaciones, o de cómo se arranca una pintura mural.

Hay algún error tipográfico en la edición, repeticiones, inexactitudes en ciertas definiciones y aplicaciones de tratamientos difícilmente justificables (la cerusa o cerusita sólo como un pigmento blanco, la cascarilla como denominación de un tipo de corrosión o la laminación como medida de (P). También se echan 
de menos entradas que deberían existir, y otras en las que solamente se aplican en relación con algunos materiales y no de otros, aun existiendo: barrido, bebedero, custodia, charnela, etc. Por otro lado, como podemos comprobar viendo la bibliografía, aunque para algunas especialidades se ha basado en textos muy recientes, en otras no tanto, echándose de menos la revisión de algunos términos, técnicas y clasificaciones ya obsoletas o algo anticuadas, cosa que esperamos y confiamos que haga en siguientes ediciones.

Reconocemos y valoramos el gran esfuerzo que supone para el autor la redacción de un texto de este tipo, aunque debido a la gran cantidad de aspectos que se ven implicados en la Conservación del Patrimonio, quizá sea necesario, para próximas ampliaciones del vademécum, el asesoramiento de expertos en temas más alejados de su formación.

A pesar de lo anteriormente dicho se trata de un libro de consulta muy manejable y de utilidad como primera toma de contacto con técnicas y procesos utilizados en nuestra profesión.

Emma García Alonso

Instituto del Patrimonio Cultural de España 